\title{
Essays on Organization, Creativity, and Globalization
}

\author{
Sungyong Chang \\ Ph.D. awarded by Columbia University, USA (May 2018)
}

\section{BIG Question:}

How does the globalization of digital innovations facilitate the discovery of talent and how can firms benefit from the globalization of digital innovations?

\section{Introduction}

Do technological advancements such as digital innovation or artificial intelligence facilitate human creativity and innovation? Global media and Internet conglomerates such as Apple and Google have been introducing new digital innovations all over the world and have been dominating the global market. As this trend has intensified, there has been a growing concern around the relationship between technological innovations and creativity. This concern has called for more systematic research on whether these new digital technologies will have a complementary relationship with human creativity, especially in firms' discovery of creative talent. My dissertation aspires to produce useful insights on how managers can leverage opportunities from the globalization of new digital innovation. To attain this goal, my dissertation first explores opportunities and threats from the globalization of digital innovations and then examines how managers can leverage such opportunities and avoid threats in talent discovery and competitive dynamics.

The emergence of platforms and media companies in the modern digital economy challenges the existing internationalization theory and practice. Due to their multisided market nature of many digital innovations, the internationalization process of platforms and media companies depends critically on local complementors (i.e., content providers) in the host country market, as well as the commitments of global platforms and media companies, which is the main focus of the Uppsala model. My dissertation investigates when global platforms are conducive to the discovery of new talent, and how global media companies may overcome the liability of foreignness and how they can overcome this liability. Thus, my dissertation attempts to contribute to a burgeoning literature in international business, specifically, the globalization of digital platforms and media companies (e.g., Johanson \& Vahlne, 2009; Alcácer, Cantwell, \& Piscitello, 2016; Chen, Shaheer, Yi, \& Li, 2019) and produce useful managerial insights.

To explore the relationship between technological innovation and human creativity, we need a better understanding of the topic of discovery of new talent. I want to emphasize that the discovery of new talent is an essential yet underexplored type of innovation. This goes back to the classic classification of innovation types proposed by Schumpeter (1934). He distinguishes among the following five types of innovation: new products, new processes, new organizations, new markets, and new resources. Most prior work focuses on the first four types of innovation. This study focuses on the last type of innovation, the discovery of new resources, in creative industries where artist talent - a type of resource - is the most important source of creativity and profit (Caves, 2000; Tervio, 2009).

This article summarizes my dissertation which examined the following three-related questions. The first essay explores how managers in music companies benefit from the globalization of the digital market for unbundled products by unleashing human creativity and innovation in local users and complementors. I utilize the staggered entry of iTunes into 29 countries to identify a causal impact of the introduction of the digital market for unbundled products. 
The second essay examines how entrepreneurs benefit from the globalization of the digital self-release market. The second essay focuses on the competitive dynamics between incumbents and entrepreneurial firms in the host country to identify opportunities and threats from the globalization of the digital self-release market. I exploit the staggered entry of YouTube into 29 countries to identify a causal impact of the introduction of the digital market for self-releases.

In the third essay, I explore how the subsidiaries of global media companies can overcome the liability of foreignness in discovering local talent in the host countries. I analyze all global media conglomerates' acquisitions of foreign country music labels during 1988-2015.

To answer these questions, I build a dataset collected and matched from multiple large-scale datasets, including the Spotify APIs, MusicBrainz, Discogs, and Quantone databases. The sample covers 165,464 artists, 2,349,776 songs, and 22,157 music companies in 29 countries for the period from 1950 to 2015 .

\section{How Can Managers Benefit from the Digital Market for Unbundled Products?}

The first essay explores the impact of the introduction of a market for unbundled products by a global platform company on experimentation and the discovery of new talent of local music companies. Digitalization has spurred a fundamental unbundling of creative industries. In the music industry, for instance, digitalization has enabled music to be purchased as both individual songs (i.e., a single) and a bundle of songs (i.e., an album). Due to the piracy problem, there is a concern that digitalization makes it more difficult for record labels to fund the release of new music. I argue that music labels, especially small local labels, can mitigate the negative impact from such a challenge by producing singles because the major bottleneck for the discovery of new music and talent is the high cost of traditional album production.

I test this idea by utilizing the staggered market entry of the iTunes Music Store into 29 countries as an exogenous shock. The introduction of iTunes has significantly increased the commercial importance of singles because music is sold in the form of individual songs that were previously only or primarily sold as parts of albums. I find that the benefit from producing singles (increased experimentation) outweighs other potential adverse effects. First, single-producing firms experiment with more new artists than album-only-producing firms. Specifically, the proportion of new artists to all artists is $27.25 \%$ (a 4.62\% point) higher in single-producing firms than in album-only-producing firms. In contrast, as information on artist talent from a one-shot unbundled experimentation is less accurate than that from albums, single-producing firms make $29.75 \%$ more omission errors. Overall, the results suggest that the positive effect from the decreased cost of experimentation outweighs the negative effect from the loss of information quality on talent; Single-producing firms discover artists with greater talent and produce more popular songs; that is, the most popular artist and song in single-producing firms are more popular than those in album-only-producing. Finally, single-producing firms are more likely to discover artists who created at least one new genre, suggesting that unbundling facilitates the creation of new markets.

The first essay exploits a unique empirical setting to make a credible causal inference about the impact of unbundling on experimentation and creativity. However, the idiosyncrasies of the music industry should not cloud the general applicability of the conceptual approach to a broad range of firms and industries. The first essay highlights how the introduction of the digital market for unbundled products changes the business environment for managers who are in charge of discovering new talent. On the one hand, the low cost of experimentation from unbundling helps small and young firms that are under financial constraints. The findings suggest that managers in small companies should leverage the low cost of experimentation and capture opportunities arisen from the market for unbundled products by experimenting with newer and more radical business ideas or projects. On the other hand, managers in large firms should cope with such threats of small and young firms by lowering the chance of missing out on talented employees or early-stage business projects in which they invested.

\section{How Can Managers in Entrepreneur- iall Firms Benefit from the Digital Market for Self-Release?}

The second essay investigates whether the digital market for self-release facilitates the discovery of talent by entrepreneurial firms in the host country. An unknown artist has trouble getting a contract with music labels that will fund money to create new music. Thanks to digitalization, artists can self-release and promote with low cost thought digital platforms. For example, artists can develop their track record and profit from views on YouTube.

Whereas a self-release market has a clear benefit for unknown artists, the self-release market may have a negative influence on the entrepreneurial firms' discovery of new talent. The comparable set of entrepreneurial firms in the music industry will be independent labels. Some independent labels were reasonably successful in discovering new talent, and these indepen- 
dent labels made a profit by producing more releases with new popular artists or being acquired by the major labels. Because the self-release market provides would-be artists with information regarding their talent, talented artists have good bargaining power when they sign a contract with a music label. For example, Elvis Presley is one of the most significant cultural icons of the $20^{\text {th }}$ century and is referred to as "the King of Rock and Roll." Because Elvis himself did not know his talent, he signed with Sun Records, a small entrepreneurial music label, in the hope of being discovered. Thus, the self-release market may make it more difficult for entrepreneurial firms to sign a contract with the next Elvis Presley because incumbent labels have better resources to attract those talented artists, such as (so-called) YouTube stars.

In testing this theory, I exploited YouTube's staggered market entry into 29 countries (the introduction of the localized version with the local language), and this study produces results from a difference-in-difference-in-differences (DDD) specification. The results suggest that the introduction of a self-release market decreases the discovery of new artists by local entrepreneurial firms. In contrast, in response to losing new talent, entrepreneurial firms increase their reliance on mediocre incumbent artists, resulting in lower average performance. The average popularity of new artists in entrepreneurial labels decreased by at least $26 \%$, and it reached a level similar to the average popularity of new artists in incumbent labels. Considering that entrepreneurial firms have relied on the discovery of new talent regarding the proportion of new artists (their proportion of new artists is approximately $20 \%$ higher than that of incumbent labels), the discovery performance of entrepreneurial labels became lower than that of incumbent labels.

There are several important takeaways from these findings. First, these findings emphasize that the digital self-release market for unknown artists inadvertently may increase competition in the resource market, resulting in entrepreneurial firms experiencing a disadvantage in discovering talented employees. Second, in the presence of a thriving self-release market like YouTube, managers in entrepreneurial firms need to put more effort and invest more money in discovering new talent and by reducing their investment in mediocre incumbent employees.

\section{Can Global Media Conglomerates Create a Synergy with Acquired Host Country Subsidianies?}

This essay examines how global media conglomerates' acquisition can create synergies with acquired foreign music labels in the discovery of new talent. A growing number of Chinese media and Internet conglomerates have been buying Korean music labels to strengthen their synergy between media technology and the popularity of K-pop. Will Chinese ownership affect the acquired Korean music labels' search for Korean talent (local market) negatively or positively? One argument suggests that global media conglomerates may undermine the discovery of new talent from the host country because these conglomerates often lack a good understanding of the host country culture. For instance, the New York Times highlighted their concern regarding Sony's liability of foreignness when Sony acquired CBS records (a US music label) in the 1980s. One columnist wrote of the Japanese, "They make good cars, TV sets, tractors. However, will they, or the executives they hire, know another Duke Ellington when they hear one?"

Although there is the liability of foreignness from foreign ownership, global media conglomerates have offsetting advantages (e.g., additional cash flow and know-how from the synergy between content and other media and technologies) that can be transferred to a foreign subsidiary. I argue that, mainly, managers in the acquired host country subsidiaries can leverage the increased capital flow media from global media conglomerates to solve the critical bottleneck in the talent discovery process: the high cost of experimenting with new artists.

I analyze global media conglomerates' acquisitions of foreign country music labels during 1988-2015. The estimates from a difference-in-differences (DD) specification suggest that, during the study period, global media conglomerates did not undermine the host country's discovery of talent that was deeply rooted in its local culture. The results suggest that global media conglomerates do not undermine the host country's discovery of local talent. In particular, except for Matsushita's acquisition of RCA in 1990, the long-term effect of the acquisitions on the discovery of local talent is either positive or null. For example, in the above case of Sony's acquisition of CBS Records in 1988, which is the first merger by a Japanese firm with a firm of a distant culture. Sony did not undermine CBS Records' discovery of domestic new talent but increased the popularity of new host country artists in CBS Records by $44.48 \%$. In contrast, Sony's acquisition decreased CBS Records' reliance on incumbent artists and foreign (outside the US) artists.

The third essay attempts to provide evidence on the benefits of synergy between content and technology can be leveraged through globalization, even in sensitive industries such as cultural industries. The first key takeaway is that although there is a growing anti-globalization sentiment throughout the world, the managers in global media conglomerates can serve the local market's tastes and desires successfully. Second, managers in global media conglomerates can create synergy between their advantages in financial resources with host country subsidiaries' local knowledge. Third, the qualitative evidence shows that host country subsidiaries' autonomy in the talent discovery process plays a pivotal role in creating synergies between the global media conglomerates and host country subsidiaries. 


\section{Conclusions and Implications}

Since the works of Hymer (1960), Vernon (1992), and Caves (1971, 1996, 2000), the nature of the relationship between multinational enterprises and innovation has always been at the heart of the theory of the multinational enterprise. I mainly explore how digital technologies have transformed and revolutionized the current business environment around the multinational enterprise. With the digital transformation, new forms of multinational enterprises have been emerging, which are unaccounted for by received wisdom in the international business literature. The global expansion of digital platforms and media companies is one of the such accounted forms. Digital platforms such as iTunes and YouTube provide an Internet-based platform to lower the cost of experimenting with new talent. The lowered cost of experimentation may or may not facilitate the discovery of new talent depending on the nature of the service and competitive dynamics between established firms and entrepreneurial firms.

The first two essays offer managerial implications for managers. These two essays demonstrate that not all digital technologies are conducive to talent discovery in small and entrepreneurial firms. The key takeaway of the first essay is that although there are benefits of unbundling, unbundling may also have a negative impact on the discovery of new talent because it will be challenging for these firms to infer an artist's true talent from a one-shot unbundled experimentation result of success or failure. Thus, managers should set an effective discovery strategy to solve this potential trade-off.

The key takeaway from the second essay is that the introduction of the digital market for self-releases mainly poses a threat to entrepreneurial firms' talent discovery process as undiscovered artists can experiment with their talent without the help of entrepreneurial firms. Thus, managers in entrepreneurial firms should invest more money in the talent discovery process and find out another source of talent discovery than the dominant self-release platform like YouTube.

Finally, the third essay offers insights on how global media companies create synergies with their foreign subsidiaries. As Ghemawat (2016) notes, even though global digital platforms offer global connectivity among users and complementors, user interactions on digital platforms are mostly domestic, and that national borders still matter in cyberspace. The third essay demonstrates how global digital platforms and media companies can overcome this paradoxical situation. The findings suggest that even though digital platforms have entered many countries and have become the dominant platform in many countries, managers in these companies should let their foreign subsidiaries put forth a substantial amount of localization effort to solve such paradoxical situations.
Alcácer, J., Cantwell, J., \& Piscitello, L., 2016. Internationalization in the information age: A new era for places, firms, and international business networks? Journal of International Business Studies, 47(5): 499-512.

Caves, R. E. 1971. International corporations: The industrial economics of foreign investment. Economica, 38(149): 1-27.

Caves, R. E. 1996. Multinational Enterprise and Economic Analysis. Cambridge: Cambridge University Press.

Caves, R. E. 2000. Creative Industries: Contracts between Art and Commerce. Boston: Harvard University Press.

Chen, L., Shaheer, N., Yi, J., \& Li, S., 2019. The international penetration of ibusiness firms: Network effects, liabilities of outsidership and country clout. Journal of International Business Studies, 50(2): 172-192.

Ghemawat, P. 2016. People are angry about globalization. Here's what to do about it. Harvard Business Review.

Hymer, S. H. 1960. The international operations of national firms, a study of direct foreign investment. Ph. D. thesis, Massachusetts Institute of Technology.

Johanson, J., \& Vahlne, J.E. 2009. The Uppsala internationalization process model revisited: From liability of foreignness to liability of outsidership. Journal of International Business Studies, 40(9): $1411-1431$.

Schumpeter, J. A. 1934. The Theory of Economic Development. New York: Routledge.

Tervio, M. 2009. Superstars and mediocrities: Market failure in the discovery of talent. The Review of Economic Studies, 76(2): 829-850.

Vernon, R. 1992. International Investment and International Trade in the Product Cycle. The Quarterly Journal of Economics, 80(2): 190-207.

Sungyong Chang (schang@london.edu) is an assistant professor of Strategy and Entrepreneurship at London Business School. He received his PhD degree in Management from Columbia University. He is interested in innovation, globalization, and computational social science. His particular focus is on the impact of the globalization of digital innovations on the discovery of talent and invention of new products in high-tech and cultural industries. 